\title{
Biosynthesis of Silver Nanoparticles from Date (Phoenix dactylifera) Seeds Extract and Evaluation of Antibacterial Activity Against Pathogenic Bacteria
}

\author{
SALEH H. SALMEN \\ Department of Botany and Microbiology, College of Science, King Saud University, \\ P.O. Box 2455, Riyadh-11451, Saudi Arabia. \\ ${ }^{*}$ Corresponding author E-mail: ssalmen@ $@$ ksu.eda.sa \\ http://dx.doi.org/10.13005/ojc/360625
}

(Received: October 06, 2020; Accepted: November 07, 2020)

\begin{abstract}
Interest in silver nanoparticles (AgNPs) has recently increased due to their extensive and varied use, the biological synthesis of synthesis of AgNPs being safer than other approaches. The Kingdom of Saudi Arabia is one of the biggest producers of date palm, leading to the production of large amounts of waste date seeds. Here, the study evaluatesthe use of date seeds extract in the biosynthesis of AgNPs and to evaluate the antibacterial effect of the resultant nanoparticles (NPs) against pathogenic bacteria. A number of which were used here in order to characterize the synthesized particles, including UV-Vis absorption spectroscopy, transmission electron microscopy (TEM) and energy dispersive spectroscopy (EDS). The results show that date seed extract can be used to synthesize AgNPs effectively. These AgNPs exhibit unique, small-size morphologies which proved to be antibacterial against pathogenic bacteria including Staphylococcus aureus, $S$. epidermidis, and Escherichia coli.
\end{abstract}

Keywords: AgNPs, Date seeds, Antibacterial activity, Pathogenic bacteria, Biosynthesis.

\section{INTRODUCTION}

Silver nanoparticles have been applied widely in numerous fields, including agriculture, biosensing, catalysis, dentistry, drug delivery, electronics, food technology medicine, photography, tissues imaging, optics, solar energy coatings and electronics ${ }^{1-3}$. The antimicrobial properties of AgNPs, encompass antibacterial, antifungal, antiparasitic, and antiviral activity ${ }^{4-11}$. They can be synthesized using a variety of chemical, physical, and biological methods, with the latter employing a wide variety of plant extracts, as well as microorganisms, such as fungi and bacteria.

Date palm (Phoenix dactylifera) has been grown in the Arab world over the last 6,000 years ${ }^{12}$. It belongs to the Arecaceae family, which includes about 200 genera containing some 3,000 species $^{13}$. In the Middle East, notably Saudi Arabia, date palm is major economic crop and food source. Seeds of the date palm fruits contain numerous essential biocompounds including fibers, sugars, fatty acids, protein, vitamins, ash, and minerals, as well as large

This is an Open Access article licensed under a Creative Commons license: Attribution 4.0 International (CC- BY). Published by Oriental Scientific Publishing Company @ 2018

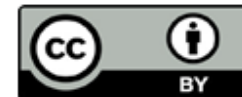


amounts of flavonoids and phenolic compounds ${ }^{14,15}$. Additionally, date seeds contain large amounts of alkaloids, saponin, anthraquinone, tannin, and terpenoids, which have antioxidant properties and free radical scavenging activities ${ }^{16}$. The widespread antitoxic effect of date palm against a range of toxins has also been demonstrated in a variety of plants and animals ${ }^{17}$.

Date seeds makes up about $6.1-11.5 \%$ of the fruit ${ }^{18}$ and are generally used only as animal feedstuffs and as a source of oils and pharmaceutical compounds. Traditionally, date seeds have been used to treat diseases such as diabetes, gastrointestinal infections, hypertension, cancer, cardiovascular disorders, hepatic infections and as a means of enhancing the body's immune system ${ }^{15,16,19}$. They also exhibit moderate antibacterial effects on pathogenic bacteria such as Escherichia coli, MRSA Staphylococcus aureus, Pseudomonas aeruginosa, Enterococcus faecalis and Bacillus cereus have been reported ${ }^{20-22}$.

The aim of this study was to evaluate the efficacy of Saudi date seed extract in the green synthesis of AgNPs, and to assess the antibacterial activity of the resultant AgNPs against pathogenic bacteria.

\section{MATERIALS AND METHODS}

\section{Materials}

Silver nitrate was obtained from (SigmaAldrich $^{\oplus}$, Steinheim, Germany). Culture media-Mueller Hinton agar, Nutrient Agar, and Nutrient Broth, were purchased from (Scharlab, S.L, Barcelona, Spain). Cultures of Escherichia coli, Staphylococcus aureus and Staphylococcus epidermidis, were obtained from the Laboratory of Microbiology, Science College, King Saud University. Sukkari dates (Phoenix dactylifera) were obtained from a supermarket in Riyadh, Kingdom of Saudi Arabia.

\section{Preparation of date seed extract}

Date seeds were removed and collected from dates using an automatic date seed removing machine. The date seeds were then washed with sterile distilled water and dried for a few days at room temperature until absolutely dry and then milled using a special machine (IKA Mills, Model: MF $10 \mathrm{~B}$, Germany). The ground powder (10 g) was then heated with $100 \mathrm{~mL}$ deionized water for $15 \mathrm{~min}$ at $80^{\circ} \mathrm{C}$. The mixture was finally filtered using filter paper (Whatman
No. 1) and the resultant solution was maintained at $4^{\circ} \mathrm{C}$ until the synthesis of AgNPs was completed

\section{Biosynthesis of AgNPs}

To a $90 \mathrm{~mL}$ aqueous solution of silver nitrate $(1 \mathrm{mM}), 10 \mathrm{~mL}$ of the seed extract was added. The mixture was then left at room temperature overnight during which time, the. color of the solution changed. The solution was then centrifuged at 13,000 rpm for 20 min to collect the AgNPs, and the nanoparticles were finally dried in an oven at $40^{\circ} \mathrm{C}$ in order to obtain AgNPs as a dry powder.

\section{UV-Visible spectral analysis}

The reduction of silver ions was determined by Ultraviolet-Visible spectroscopy (UV-Vis), the absorbance spectrum between 200 to $800 \mathrm{~nm}$ being recorded using Thermo Scientific ${ }^{\mathrm{TM}}$ BioMate $^{\mathrm{TM}} 160$ UV-Visible Spectrophotometer.

\section{Energy dispersive spectroscopy (EDS)}

For EDS measurements, the single particles were investigated by JEOL JSM-6380 LA SEM. Prior to the measurement, the AgNPs sample was drop-cast on a copper substrate.

\section{Transmission electron microscopy (TEM)}

TEM images were achieved using a JEOL microscope (JEM-1011), with an accelerating voltage of $80 \mathrm{keV}$. Prior to imaging, the samples were dried under vacuum (Model 1:53 liter vacuum oven, Vinci Technologies, France).

\section{Antibacterial activity of AgNPs}

The antibacterial activity of AgNPs was determined using the agar well-diffusion method ${ }^{23}$ with minor modifications. Mueller Hinton agar was used and wells were loaded with $100 \mu \mathrm{l}$ synthesis AgNPs. The agar was then covered with the bacterium under test and incubated at $37^{\circ} \mathrm{C}$ for 24 hours. Any inhibition zones which developed around AgNPs-loaded wells were then measured.

\section{RESULTS AND DISCUSSION}

\section{Visual observation of biosynthesis}

A color change from light brown to dark brown was observed when the date seed extract was added to the silver nitrate solution Fig. 1. Such a color change is likely due to the excitation of surface plasmon vibrations, which is widely used as an indicator of the synthesis of silver nanoparticles ${ }^{24,25}$. 


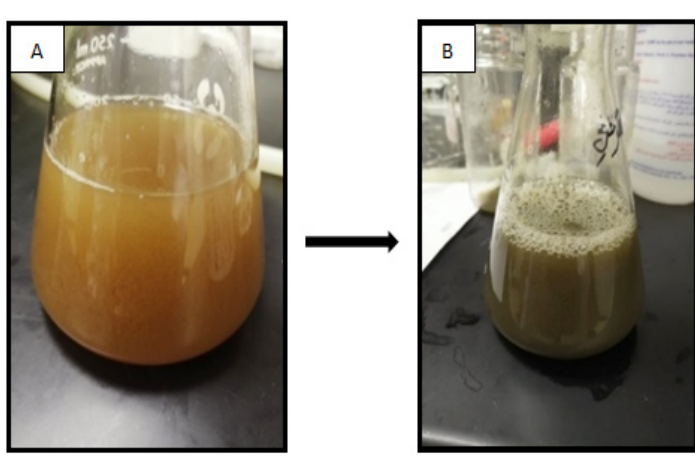

Fig. 1. Solution of silver nitrate $\left(\mathrm{AgNO}_{3}\right)$ with date seeds extract. (A) The solution prior to the reaction and (B) immediately after the reaction

Numerous studies using a range of plant extracts have confirmed that a color change occurs due to the formation of metal nanoparticles, following the reduction of precursor ions in the solution ${ }^{6,26-29}$. The potential of the date seeds extract to alter the silver nitrate solution to AgNPs is likely due to the presence, in the date seed extract, of numerous bioactive compounds, including flavonoids, polyphenols, phenolics, anthraquinone, tannin, carboxylic acids, proteins, saponin and aldehydes. ${ }^{2,3}$

\section{UV-Vis Spectrophotometer Analysis}

UV-Vis spectroscopy was employed to characterize the AgNPs synthesized when using date seeds extract. The formation of AgNPs was seen over the wavelength range of 200 to 800 $\mathrm{nm}$. Fig. 2 shows the surface plasmon absorption band which exhibits a peak at $400 \mathrm{~nm}$ following overnight incubation. Absorption spectrum maxima of AgNPs are generally recognized to fall within the range of 400-500 $\mathrm{nm}$ a result generally considered to be due to surface plasmon resonance ${ }^{30,31}$. The results presented here are therefore similar to those reported earlier. ${ }^{31,32,27,26,33}$

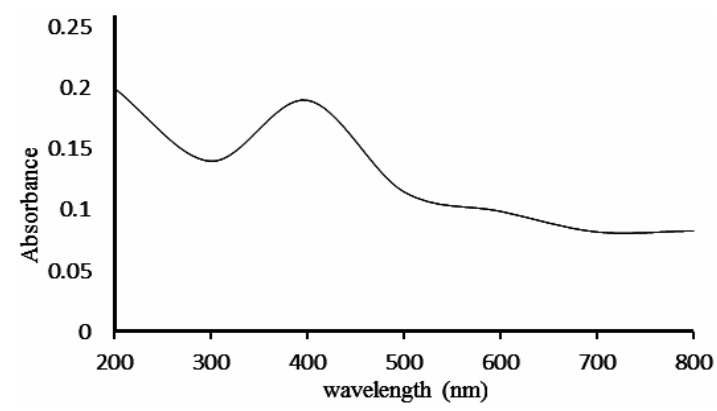

Fig. 2. UV-Visible spectrum of biosynthesized AgNPs by date seeds extract

\section{Energy dispersive spectroscopy analysis}

Energy dispersive spectroscopy was used to analyze the composition of AgNPs. I noted extreme signals from the $\mathrm{Ag}$ atoms at about $3 \mathrm{keV}$, which show that the nanoparticles were indeed AgNPs. The signals at around $0.5 \mathrm{keV}$, corresponding to carbon and oxygen from date seeds extract, were also observed Fig. 3. It is possible that the signals from carbon and oxygen originated from $\mathrm{X}$-ray emissions of bioactive compounds present in the date seed extract. Our results are similar to those reported by ${ }^{34}$ in studies on the green synthesis of AgNPs using date palm fruit extract. For example, the EDS data confirmed the effective synthesis of AgNPs, while the EDS signal of mineral Ag nanocrystallites usually appears at $3 \mathrm{KeV} .^{35,36}$

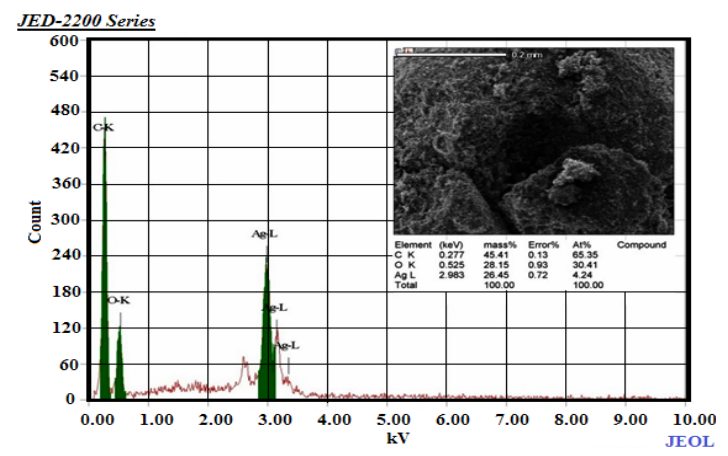

Fig. 3. EDS analysis of AgNPs synthesized using date seeds extract

\section{Transmission Electron Microscopy analysis}

Transmission Electron Microscopy is generally used to determine the exact size and to reveal structural information about nanoparticles. As a result, TEM was used here to observe the shape and size of the AgNPs which were biosynthesized using date seeds extract. The TEM images showed that AgNPs exhibited a spherical morphology, with diameters ranging from 7-37 nm Fig. 4. A number of studies commenting on the shape and size of AgNPs synthesized using extracts from plants have produced results similar to the ones reported here. ${ }^{34,26,33}$

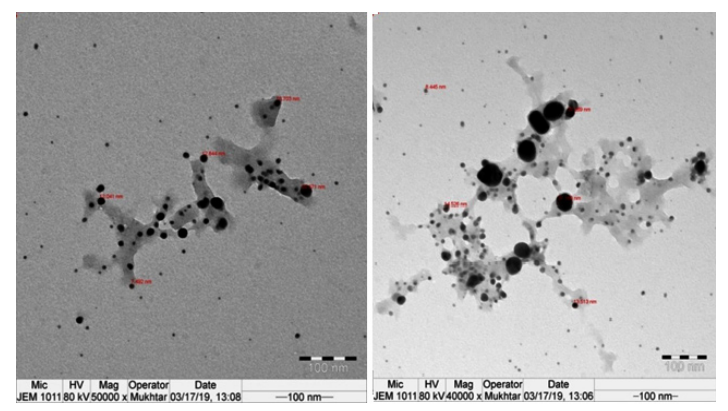

Fig. 4. TEM images of AgNPs synthesized using date seeds extract 


\section{Antibacterial activity of AgNPs}

Figure 5 shows the antibacterial activity of AgNPs against the three bacteria used here. AgNPs produced the most marked against $S$. epidermidis. Similar findings have been found in studies where the antibacterial activity of plant-biosynthesized AgNPs has been reported. ${ }^{35,36,27,34,26,33}$

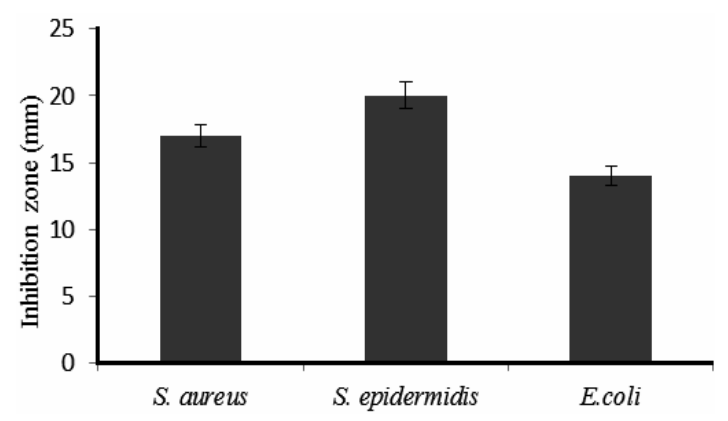

Fig. 5. Antibacterial activity of synthesized AgNPs against pathogenic bacteria

\section{CONCLUSION}

Saudi Arabia is one of world's major producers and waste date seeds. Here the study reports the biosynthesis of AgNPs using extracts from Saudi date seeds, the morphological features of the resulting AgNPs being characterized using a variety of techniques. In addition to demonstrating the utility of date seed extract for AgNP green synthesis our results show that the resultant nanoparticles are spherical shape and small in size and exhibit antibacterial activity against $S$. aureus, S. epidermidis and E. coli.

\section{ACKNOWLEDGMENT}

The author thanks the Deanship of Scientific Research and RSSU at King Saud University for their technical support.

\section{Conflict of Interest}

The author declare no conflict of interest.

\section{REFERENCES}

1. Shameli, K.; Ahmad, M. B.; Zamanian, A.; Sangpour, P.; Shabanzadeh, P.; Abdollahi, Y.; Zargar, M. Int. J. Nanomedicine., 2012, 7, 5603-5610.

2. Zia, F.; Ghafoor, N.; Iqbal, M.; Saliha, M. Appl. Nanoscience., 2016, 6, 1023-1029.

3. Jyoti, K.; Baunthiyal, M.; Singh, A. J. Radi. Res. Appl.Sci., 2016, 9, 217-227.

4. Ansari, M.A.; Khan, H.M.; Khan, A.A.; Malik, A.; Sultan, A.; Shahid, M.; Shujatullah, F.; Azam, A. Biol. Med., 2011, 3, 141-146.

5. Kim, K.; Sung, W.S.; Suh, B.K.; Moon, S.J.; Choi, J.G.; Kim, D.; Lee, G. BioMetals., 2009, 22, 235-242.

6. Jalal, M.; Ansari, M.A.; Ali, S.G.; Khan, H.M.; Eldaif, W. A.; Alrumman, S.A. Int. J. Adv. Res., 2016, 12, 428-440.

7. Khatami, M.; Pourseyedi, S.; Khatami, M.; Hamidi, H.; Zaeifi, M.; Soltani, L. Biores. Biopro. J., 2015, 2, 1-7.

8. Lara, H.H.; Ayala-Nunez, N.V.; IxtepanTurrent, L.; Rodriguez-Padilla, C. J. Nano biotechnology., 2010, 8, 1-10.

9. Trefry, J.C.; and Wooley, D.P. J. Virol. Methods., 2012, 183, 19-24.

10. Marimuthu, S.; Rahuman, A.A.; Rajakumar, G.; Santhoshkumar, T.V.; Kirthi, A.; Jayaseelan, C.; Bagavan, A.; Zahir, A.; Elango, G.;
Kamaraj, C. Parasitol Res., 2011, 108, 1541-1549.

11. Huy, T.Q.; Thanh, N.H.; Thuy, N.T.; Chung, P.V.; Hung, P.N.; Le, A.T.; Hanh, N.H. J. Virol. Methods., 2017, 2, 4152-4157.

12. Copley, M.S.; Rose, P.J.; Clampham, A.; Edwards, D.N.; Horton, M.C.; Evershed, R.P. Proc. Biol. Sci., 2001, 26, 8593-597.

13. Barreveld W.H. FAO Agricultural Services Bulletin No., 2015, 3, 101.

14. Al-Farsi, M.; Alasalvar, C.; Al-Abid, M.; AlShoaily, K.; Al-Amry, M.; Al-Rawahy F. Food Chem., 2007, 10, 4943-947.

15. Bouhlali, E. T.; Alem, C.; Ennassir, J.; Benlyas, M.; Mbark, A.N.; Zegzouti, Y. F. J. Saudi Soc. For Agric. Sci., 2017, 16, 350-357.

16. Adeosun, A.M.; Oni, S.O.; Ighodaro, O.M.; Durosinlorun, O.H.; Oyedele, O.M. J. Taibah Univ. Med. Sci., 2016, 1, 11-6.

17. Yasin, B.R.; El-Fawal, H.A.; Mousa, S.A. Int. J. Mol. Sci., 2015, 16, 30075-30090.

18. Habib, H.M.; Ibrahim, W.H. Int. J. Food Sci. Nutr., 2009, 60, 99-111.

19. Duke, J. A. Herbal Reference Library, CRC Press, FL., 1992.

20. Sundar, R.V.; Segaran, G.; Shankar, S.; Settu, S.; Ravi, L. Int. J. Green Pharm., 2017, 11, S292-S297. 
21. Saleh, F.R. J. Bio. Innovation., 2016, 5, 313318.

22. Bentrad, N.; Gaceb-Terrak, R.; Rahmania, F. Natu. Prod. Res., 2017, 31, 2544-2548.

23. Valodkar, M.; Nagar, P.S.; Jadeja, R.N.; Thounaojam, M.C.; Devkar, R.V.; Thakore, S. 2011, 384, 337-344.

24. Ahmad, A.; Mukherjee, P.; Senapati, S.; Mandal, D.; Khan, M.I.; Kumar, R.; Sastry, M. Colloids and Surfaces B: Biointerfaces., 2003, 28, 313-318.

25. Li, S.; Shen, Y.; Xie, A.; Xuerong, Y.; Lingguang, Q.; Li, Z.; Qingfeng, Z. Green Chem., 2007, 9, 852-858.

26. Tarad, A.A.; Sulaiman, A.A.; Salmen, S.H.; Wainwright. M. Biotechnol Biotec Eq., 2017, 31, 411-417.

27. Ali, S.G.; Ansari, M.A.; Khan, H.M.; Jalal, M.; Mahdi, A. A.; Cameotra, S.S. J. Basic. Microbio., 2017, 57, 193-203.

28. Chen, Y.; Tang, J.; Liu, X.; Ren, X.; Zhen, M.; Wang, L. Materials., 2019, 12, 1-12.
29. Hussain, A.; Alajmi, M. F.; Khan, M.A.; Pervez, S. A.; Ahmed, F.; Amir, S.; Husain, F.M.; Khan, M.S.; Shaik, G. M.; Hassan, I.; Khan, R. A.; TRehman. Front. Microbiol., 2019, 10, 1-19.

30. Sastry, M.; Mayya, K.S.; Bandyopadhyay K. Colloids Surf. A Physicochem. Eng. Aspects., 1997, 127, 221-228.

31. Bankar, A.; Joshi, B.; Kumar, A.R.; Zinjarde S. Colloids Surf. A Physicochem. Eng. Aspects., 2010, 368, 58-63.

32. Zaheer, Z.; Rafiuddin. Colloids and Surfaces B: Biointerfaces., 2012, 90, 9048-9052.

33. Ansari, M.A.; Alzohairy, M.A. Evid Based Complement Alternat Med., 2018, 1, 860-280.

34. Farhadi, S.; Ajerloo, B.; Mohammadi, A. Acta Chimica Slovenica., 2017, 64, 129-143.

35. Deenadayalan, A. K.; Palanichamy, V.; Selvaraj, M. R. Spectrochimica Acta Part A., 2014, 127, 168-171.

36. Liao, J.; Zhu, Z.; Anchun, M.O.; Lei, L.; JingChao, Z. Int. J. Nanomedicine., 2010, 14, 261-267. 